\title{
A los 25 Años de la Desaparición de dos Grandes Escritores Peruanos
}

RICARDO PALMA (1833-1919)

\begin{abstract}
A cumplirse el vigésimoquinto aniversario de la desaparición de don Ricardo Palma, es deber de los peruanos - y acaso también de los americanos - meditar serenamente acerca de las virtualidades de la obra magnífica legada por ese esclarecido creador de arte. Han transcurrido ya los años en que su obra significativa, las Tradiciones peruanas, pudo juzgarse con más o menos prejuicio, con más o menos apasionamiento banderizante. Entra ya su obra en la categoría de los valores inconmovibles, más allá de la persona grata o ingrata, más acá de los juicios apresurados o convencionales. Si algún debate se suscitara todavía, no incidiría sobre la validez artística ni sobre la congruencia vital de la obra dejada a la posteridad. Palma tiene ya el rango de monumento nacional. Negarlo significaría lo mismo que negar la gloria de Miguel Grau o la estela heroica de Simón Bolívar, porque los valores de la acción, que es también espíritu, se confunden con los valores de la creación, cuando ésta se vincula como la de Palma con el ser mismo de la raza y de la vida nacional. No pensemos, de otro lado, que Palma sea multivalente, porque nadie lo es a riesgo de ser incompleto y deficiente en algo. Los grandes autores, y aun los genios, tienen sus limitaciones porque fueron humanos y no dioses. No caigamos, pues, en el error de pretender que Palma nos resuelva todas nuestras aspiraciones presentes ni que se incorpore, a cinco lustros de su muerte, a nuestras inquietudes
\end{abstract}


actuales. Juzguémoslo dentro de su época, al lado de las gentes que lo rodearon, que eran otras que nosotros, envuelto en sus problemas que eran distintos de los de ahora. No nos detengamos en sus flaquezas si las tuvo; miremos a su grandeza renovada con el tiempo, acrecida con el transcurso de los años. Pensemos en su obra henchida de realidades nuestras, tal vez doradas algunas, pero siempre peruanas, a fuerza de optimismo y de fe en lo que fuimos y en lo que seremos. Meditemos en esa lección permanente de peruanidad que es su obra labrada en hechos y sangre perulera, atenta siempre al ánimo de perpetuar la vida peruana de otros tiempos y a influir la vida peruana de tiempos mejores. Ahondemos en esa enseñanza suya que nos trae su consagración a las cosas del espíritu y de la cultura y en ese desprendimiento de los bienes materiales que lo llevó a morir pobre. Porque supo ser hombre digno y de grande altitud moral, su obra tiene el respaldo y el amparo de las manos y del cerebro que la concibieron plácidamente, sin rencores ni veleidades, sin resentimiento ni acritud, con generosidad y con largueza singulares, lejos de inhibiciones o de hipocresias.

En esta hora de aniversario se excluye, pues, el reproche o el halago; está presente sólo la obra impersonalizada y descarnada de pasiones. Vemos clara su magnitud, su trayectoria y su proyección. Nada limita ya su perspectiva recta y cristalina, perfecta e ilimitada para lo futuro.

Palma es el primero de nuestros escritores que sintetiza genuinamente el genio nacional, con los medios más simples, valiéndose de la anécdota, del episodio fugaz, de la historieta divertida o del retazo o la migaja de la historia patria. Nada tan lejos de él como la afectación insincera, como la solemnidad de grave contorno, como el dogmatismo excluyente o la oquedad del término sin contenido. Toda expresión suya se nutre de sustancia y savia, todo giro luce esa sabiduría que no está en los libros sino en la vida, toda palabra representa la idea precisa, todo vocablo o dicho popular se sitúa en el sitio y en la oportunidad debida. Nada falta y nada sobra en una "tradición" de Palma. Era un escritor atildado pero sin forzamiento y era popular sin vulgaridades. Unos lo llaman el clásico de nuestras letras, pero sin desconocer su fina raíz romántica. Otros. lo conocen como el romántico espontáneo, pero sin negar la clásica estirpe de su corte galano y castizo. Gran escritor de la lengua castellana, sabía juntar a ella el más neto sabor nacional de su prosa. 
Muy peruano en su ser, guardaba no obstante la línea de cultor de aquella lengua que le hacía comprensible aquí o allá, fuera de los límites del Perú. Muy hondo en sus mirajes de la humana naturaleza, era y es fácilmente captable por el adulto y por el niño, por el hombre culto y por el hombre sin cultura. Conocedor del espíritu humano como pocos, sus tipos pertenecen a todas las clases sociales, desde el inca y la ñusta hasta el mitayo, desde el virrey al campanero, desde el aristócrata hasta el artesano, desde el general hasta el "montonero", desde el poderoso hasta el desvalido, desde el niño al anciano, desde el personaje ilustre hasta el hombre de la calle. Pocos escritores han practicado una más sustantiva democracia como el "tradicionista" en sus escritos.

Palma es un escritor de cristalina conciencia de hombre. Ninguna amargura, ningún reproche, ninguna impertinencia personalista enturbia sus escritos. Prevalecía siempre el genio amable, el trato cordial en todos sus muñecos, el rasgo optimista en sus narraciones, la enseñanza estimulante y simpática. Si debía presentar las flaquezas humanas, derivaba de ellas algo pintoresco. Si tenía que habérselas con las arrogancias o las grandezas del genio, las exponía en tal forma que la actitud fuera enseñanza fecunda para todos. Buscaba el lado más humano de los seres y el más grato de las situaciones. Por él, muchos han aprendido a querer la vida y a pensar que vale la pena de ser vivida.

De aquí que haya llegado a ser Palma el escritor más amado y más conocido de los peruanos, aquel que no solamente se lee en las bibliotecas, sino además aquel que deleita en el hogar. El autor que es comprendido por los adultos y querido por los niños. En sus páginas está viviendo nuestro país; en sus personajes se encuentra el derrotero del espíritu humano con sus grandezas ejemplares y sus miserias emocionantes.

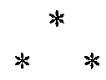

Dentro de la generación romántica de 1848 , que Palma caracterizó con animación sin par en su libro La bohemia de mi tiempo, surgieron temperamentos de singular prestancia literaria como Carlos Augusto Salaverri, José Arnaldo Márquez, Clemente Althaus y el propio Ricardo Palma. El último emerge de esa generación román- 
tica como el mejor dotado. Pero es significativo que su aureola literaria no es conseguida por el poeta de musa sentimental ni por el satírico de rica veta, sino por el prosador. Palma se afirma y se define en el mundo de las letras peruanas y americanas con una original modalidad de prosa de nuevo tipo y calidad excelente: las Tradiciones peruanas, que su hija Angélica logró editar en Madrid, en seis volúmenes bellamente impresos e ilustrados.

De su actividad juvenil de poeta romántico, quedan dos libros suyos que se titulan Armonias y Pasionarias, que constituyen el pórtico de su faena literaria, sombreado intensamente por la estructura del edificio de sus libros posteriores en prosa. Luego irrumpe Palma en la prosa, tentado por la sugestión que entonces despierta la "leyenda" romántica. Busca en lo nativo el tema que los poetas españoles habían hallado en la Edad Media. Y nace de la evocación de las épocas pretéritas del" Perú, su leyenda incaica Palla-Huarcuna, en rigor su primera "tradición". Desde esa fecha, 1860, escribe este tipo de relatos breves, que van siendo cada vez más originales y más desligados de los precedentes en géneros afines, adquiriendo fisonomía propia a lo largo de medio siglo de producción. La Prensa de Buenos Aires publica, en 1915, su "última tradición": Una visita al Mariscal Santa Cruz. Se había logrado una obra perdurable y se había consagrado y definido en cincuenta años un nuevo género literario. Estaba creada, como dice Ventura García Calderón, "una breve historia del Perú novelada". Y es, además, significativo que tal ciclo de actividad literaria se inicie con la evocación de un ambiente y una escena del Incario y se concluya con un relato que juega en plena época republicana. Era el Perú de un extremo al otro, desde lo más antiguo a lo más reciente, en una síntesis amalgamada con gracia y con talento literario.

Las "tradiciones" de Palma han sido consideradas por la crítica como un nuevo género narrativo, en que la historia y el cuento se vierten en sugerente mezcla. La "tradición" se sustenta en un hecho cierto o una anécdota peregrina, hallada generalmente en los antiguos documentos con que Palma estuvo en contacto en los archivos de la Biblioteca Nacional, de la que fué director por muchos años. El hecho o la anécdota eran luego adornados con situaciones ficticias, personajes afines o inventados, letrillas alusivas, adaptadas o propias, diálogos muy agudos y una gran dosis de genio artístico que fundía en un todo esos elementos. 
Palma no es sólo el escritor peruano más leído en el país, sino igualmente el más conocido en el extranjero. Muchos extraños han adquirido, a través de él, la primera noción de esta tierra y acaso muchos viajeros asomaron su curiosidad a estas costas peruleras, por su culpa. Por él se disiparon muchas ignorancias, se rectificaron yerros y acaso también se forjaron rosadas versiones de sus realidades pretéritas; empero, se dulcificaron muchas impresiones infelices, perennizaron cosas grandes cuya apariencia mezquina condenaba al olvido. Por acción de Palma, cobra aire de grandeza lo que la facundia popular peruana habíase empeñado en denigrar; vibra con vuelo propio el sentir del costeño; dáse como espectáculo digno de ser visto el de los usos y costumbres típicos, y adquieren vida muchas cosas suyas y nuestras que el tiempo iba desvaneciendo.

$\mathrm{Su}$ facilidad para llegar a la masa popular se atribuye a su mensaje de gracia y simpatía, de acopio de elementos vernáculos y de identificación íntima de su musa con el genio nacional del mestizo. En verdad que todas estas cualidades condicionan su éxito; pero no se ha reparado lo bastante en la identificación del pueblo con Palma, dictada por esa sabiduría popular que distingue sin equivocarse, por obra de un seguro instinto, entre lo verdadero y lo falso, entre lo original y lo manido.

La capacidad para ser original fué en Palma tan neta y rotunda que hasta en las formas y ya no solamente en los temas, dió la impresión y constituyó la realidad de un nuevo y brillante autor literario, de un estilo único y de una forma literariamente nueva: el género narrativo por él creado, que fué la "tradición".

Palma tuvo la intuición de muchas realidades literarias de nuestro tiempo. Por la época en que Palma concluía su obra, surgía en Inglaterra, alrededor de 1910, el nuevo molde de un género nuevo: la biografía novelada, que ha sido la forma literaria de más grande éxito en nuestros días. André Maurois y otros escritores han señalado las particularidades que distinguen a la biografía actual y todo conduce a pensar, al releer en Palma la de don Francisco de Carvajal -el desalmado lugarteniente de Gonzalo Pizarro y sanguinario caudillo de la conquista, conocido como "el demonio de los Andes"-, si Palma no se adelantó en cierto modo a esas tendencias últimas de la biografía, al utilizar con donaire la anécdota mejor definidora del personaje que los largos y aburridos parlamentos, al subsanar con la creación imaginaria lagunas insubsanables que dejan los datos 
de la historia, al reconstruir el diálogo pleno de vitalidad y recoger la genialidad recurrente del personaje.

Palma es a la vez el escritor selecto y el escritor de la multitud. Unía el cuidado de la dicción con la frescura y vitalidad del tema. Realizaba al par el ideal clásico de don Andrés Bello, quien clamaba por la expresión perfecta, y el ideal de otro grande y auténtico americano, don Domingo Faustino Sarmiento, escritor rudo de realidades, de sangre y de idea.

Su aptitud hábil para captar la entraña viva de lo pertuano como sutil para crear formas nuevas en que recogerla, le hace una de las primeras figuras de las letras americanas. Su influencia en América no se ha estudiado aún, pero él mismo pudo alcanzar a comprobar cómo tras su estela de creador, surgieron "tradicionistas" múltiples en todas las latitudes de nuestro continente y era imitado y seguido fuera de las fronteras de la patria.

No solamente ha sido Palma un vencedor del espacio, trasponiendo con su celebridad la raya fronteriza. También ha sido un vencedor del tiempo. Al cuarto de siglo de su desaparición, su recuerdo es más vivo entre los peruanos y las letras de América lo reclaman un clásico del continente y del idioma, como lo testimonia la bella antología intitulada Flor de Tradiciones, que recientemente editaron George W. Umphrey y Carlos García-Prada, como volumen iv de la Biblioteca de CLÁsICos DE AmérICA, que publica el Instituto Internacional de Literatura Iberoamericana.

II

ABRAHAM VALDELOMAR (1888-1919)

Valdelomar es el representativo de la inquietud de renovación en nuestro medio. Su extraordinaria capacidad literaria hace que Valdelomar inscriba su nombre en los anales literarios del Perú, no obstante las imperfecciones y contingencias de una obra en gran parte fragmentaria y destinada al periodismo, desarrollada en sólo 31 años de vida. Pocos escritores del Perú han podido realizar, en lapso semejante, una obra literaria tan estimable en cantidad y calidad. Pensemos por un momento en lo que había producido a dicha edad Palma (en 1864), González Prada (en 1879) o José Santos Chocano (en 1902). El primero acababa de escribir algunas "tradi- 
ciones", el segundo no había escrito ninguno de sus libros salvo Minúsculas, todavía inédito, y el tercero no había ofrecido aún a la publicidad su primer libro definitivo: Alma América, aparecido sólo en 1906. Esta comparación de fechas no es, sin embargo, un recurso para regatear el mérito a nadie, en beneficio de alguien, pero sirve de referencia para ayudar a la imaginación a reconstruir el concepto de la.valoración de un autor prematuramente desaparecido, como Valdelomar. Hay otros casos de lamentables y prematuras desapariciones en la literatura peruana, que en modo alguno se ha caracterizado por la longevidad de sus representantes, como el de Mariano Melgar, esclarecido precursor del romanticismo con treinta años de anticipación, que perfiló obra definitiva a los 26 , y el de Enrique Alvarado, que fué promesa brillante antes de los 25. Acaso si Palma con sus 86 años de vida confirma con su excepción la regla de que los escritores peruanos, con obra de calidad, mueren casi siempre jóvenes, sin tener la oportunidad que Palma logró de concluir una trayectoria intelectual.

La vida inquieta de Valdelomar tuvo el reiterado presentimiento de su pronto y precoz final. A cambio de la limitación del tiempo parece haber mediado, como compensación, la multiplicidad de su inquietud, su fervor en la producción y su admirable laboriosidad en casi todos los campos de la actividad intelectual.

Desde las aulas escolares, como "guadalupano" insigne, ya esgrime la pluma o el pincel antes de los 15 años, para aparecer luego como dibujante de excelente factura, al lado de Málaga Grenet, en Monos y Monadas y antes en Aplausos y Silbidos. Hasta 1913, en que Valdelomar emprende el viaje a Italia, como secretario de Legación, había ya colaborado en las revistas más estimables de Lima: Actualidades, Letras, Gil Blas, Ilustración Peruana, Variedades y en un semanario de módestísima factura pero de inolvidable inquietud, Balnearios, que dirigía Alfredo Muñoz en Barranco. Su colaboración se prodigaba en poesías, en crónicas como las que tituló "Con la argelina al viento" - en que vuelca su experiencia de soldado durante la movilización en 1910, junto con la de otros intelectuales jóvenes actiartelados - y hasta en algún ensayo de novela como La ciudad de los tísicos, desconcertante trama, con insinuaciones decadentistas a la Lorraine, que, publicada en varios números de $V$ ariedades, no ha visto aún la luz en volumen. Además publicó una novela corta, Ciudad muerta, y empezó a revelarse un cuentista excelente. La 
política lo envuelve luego y lo beneficia. Vinculado a la candidatura presidencial que triunfa en 1912, Valdelomar emprende el año siguiente el viaje a Europa. En Italia se desenvuelve su actividad más perdurable. Su sensibilidad se afina con la nostalgia de la tierra lejana y nace en Roma "El Caballero Carmelo", tal vez el cuento más perfecto y emotivo que se ha producido en el Perú, una pequeña obra maestra.

Sucede en Valdelomar lo contrario de lo que suele suceder con los espíritus mediocres que se deslumbran con la experiencia europea. Si Valdelomar había sido "dannunziano" antes del viaje, en Roma deja de serlo. Si antes había sido permeable a la influencia decadentista de otros escritores "fin de siglo", en Europa se revela y define su personalidad y comienza a ser Valdelomar. Claramente lo vemos así a su regreso. Entonces comienza la nueva etapa y la definitiva en su vida, aquella que al decir de César Vallejo, "apunta una nueva época en la literatura peruana". Comienza su colaboración asidua y trascendente en La Prensa, en secciones que no deja envejecer ni en el título ni en la forma. El lector común inclusive busca insistentemente sus "Comentarios" o sus "Palabras", sus "Crónicas frágiles", sus "Impresiones", sus "Fuegos fatuos", sus "Diálogos máximos" y "Al margen del cable". Su actividad es múltiple. Es el periodista, pero al mismo tiempo el escritor de calidad, que colabora en las mejores revistas del continente, que dirige una revista memorable, Colónida, en 1916, y que empieza a publicar libros.

Colónida -que da nombre a la generación que acoge en sus páginas y que tiene por líder a Valdelomar- constituye un momento trascendental en la literatura pertana. "Representó - ha dicho Mariátegui, uno de sus colaboradores y exégetas - una insurrección contra el academismo y sus oligarquías, su énfasis retórico, su gusto conservador, su galantería dieciochesca y su melancolía mediocre y ojerosa. No fué un grupo, no fué un cenáculo, no fué una escuela, sino un movimiento, una actitud, un estado de ánimo." Colónida concretó y definió el ideal perseguido y realizado sólo en parte de dos importantes revistas literarias anteriores, editadas por Enrique Bustamante y Ballivián: Contemporáneos en 1909, y Cultura en 1915.

Puede decirse que en Colónida nace la nueva literatura del Perú. Ella está en la encrucijada entre lo viejo y lo nuevo. Acoge todo lo anterior que algo representaba y que debía quedar a la posteridad. No excluye to que tiene valor permanente. Pero al mismo tiem- 
pc intuye el futuro y promueve y estimula lo que ha de venir, exaltando los valores que en tiempos venideros han de ganar la fama, pese a la incomprensión de los críticos oficiales. Tal es el caso de José María Eguren, cuyo nombre es proclamado por vez primera como la más auténtica realidad poética de los últimos tiempos.

Entretanto, Valdelomar publica su primer libro, La Mariscala (Talleres de la Penitenciaría, Lima, 1915), que es la insinuación de una biografía novelada, tal vez poematizada, de una mujer de la historia, doña Francisca Zubiaga de Gamarra, presidenta del Perú. Le sigue El Caballero Carmelo (Talleres de la Penitenciaría, Lima, 1918), en que reúne, bajo el título ya conocido, una colección de sus cuentos, con prólogo de Alberto Ulloa y un apéndice crítico. Allí figuran sus cuentos de ambiente costeño, sus cuentos yanquis, sus cuentos chinos y sus cuentos incaicos, en sucesivas secciones. Poco después aparece Belmonte, el trágico (Lima, 1918), ensayo de una estética futura a través de un arte nuevo.

Probablemente, si revisamos nuestra literatura posterior, encontraremos libros mejor escritos, pero no libros que signifiquen tan grande inquietud ni tan grande reacción contra la estulticia y el desdén generalizado por la actividad artística y tan formidable esfuerzo por desechar lo anecdótico en pos de la categoría, lo cursi en pos de lo selecto y refinado. Completa la bibliografía de Valdelomar un libro de póstuma edición que reúne, en un volumen, sus cuentos de ambiente incaico bajo el título Los hijos del Sol (Lima, Ed. Euforión, 1921).

Por sobre todo sentimiento de escuela o tendencia literaria, por sobre las influencias europeas que en una época lo embargaron, Valdelomar vió siempre al Perú, su tierra y su hombre. Sentía como nadie el concepto de patria como una continuidad en el tiempo y una totalidad en el espacio. Tuvo el orgullo de ser peruano al par que también, y sin resentimiento alguno, tenía a honra proclamar su origen modesto y su pobreza familiar. Su aristocratismo era formal y convencional. Era simple recurso para anonadar a los "burgueses", mas no para engañar al prójimo. Cuantas veces pudo, solía aproximarse al pueblo y dejarse comprender por el pueblo.

Si en alguna ocasión había dicho: "La función del artista, y en este caso del poeta, es descubrir por el sentimiento lo que la naturaleza tiene de eterno y esquivo", sabía practicar este principio lealmente con respecto a su propia tierra: para él, la naturaleza era la 
que había vivido y había nutrido sus años infantiles, la costa y el mar peruanos, y también los Andes y todo su Perú, en fin, sin recurrir a paisajes artificiales o extraños, sin tratar nunca de descastarse.

Al cuarto de siglo de la desaparición de Valdelomar, podemos apreciar y valorizar algo más que "la proeza periodística" de que nos habla Luis Fabio Xammar en el sugestivo y hasta ahora único estudio integral que existe de la personalidad de Valdelomar (Valdelomar: signo, Lima, Ed. Sphinx, 1940). Acaso alcanzó a lograr la más brillante "proeza literaria" de los últimos tiempos, por la calidad de la obra, por la cuantía y afanosa dedicación a ella, por la influencia que proyecta.

Es mérito perdurable de Valdelomar no sólo haber multiplicado su actividad periodística, y haber en general dignificado literariamente el periodismo, en todas las formas posibles, sino también haber sabido mantener una alta calidad de selección artística en todos sus escritos y haber sabido grabar el sentido de lo eterno en la fugacidad de la crónica, lo esencial en medio de la levedad. Es también proeza literaria haber insurgido contra lo adocenado y lo yerto, rompiendo cánones y fustigando valores sin mérito. Es igualmente proeza literaria el haber llegado al pueblo no obstante la exigencia de su gusto estético. Porque Valdelomar supo hacer arte sin melodrama, sin complicación innecesaria, sin retorcimiento alguno, con los medios más sencillos, logrando la' categoría sin enrevesamiento.

Igual que Palma, es un escritor que se deja comprender de todos, a quien el hombre común pudo gustar y sentir sin dificultad ni tropiezo, porque el autor había sabido acercarse a la emoción del pueblo y el espíritu de la nación. Asimismo cautiva y arranca el aplauso de los niños, atentos oyentes o lectores de las hazañas del sin par Caballero Carmelo o de los giros pintorescos de la leyenda de la bandera nacional. Niño pobre y sin pan ni alegrías fué aquel que nació en 27 de abril de 1888, aunque con anhelo de mar, de belleza y de infinito; conciencia limpia de niño prodigioso fué la que se apagó trágicamente, no un viernes santo como la de César Vallejo, sino un dos de noviembre, día de difuntos, en Ayacucho, "rincón de los muertos", del año de 1919. Su alma ha quedado y perdurará como una oriflama de acción, de consecuencia artística, de lealtad con sus principios estéticos, de aliento de renovación y de vida.

Estuardo NúÑ̃z, Lima. 